\title{
广西资源县河灯歌节研究
}

闭晓静 邓环

广西民族大学科技史与科技文化研究院

DOI:10.32629/ems.v2i4.1594

[摘 要] 河灯节的由来与宗教及当地的生活条件关系十分密切, 苗族歌节融合了苗寨人民日常生活和精神信念, 资 源县政府将两者嫁接发展为一个旅游项目一一河灯歌节,在几十年间获得了积极的市场反响。但随着社会的进步,河 灯歌节在流程仪式、红利覆盖范围、文化内涵、继承发展等方面显现出了不足, 市场竞争力逐渐减弱。本文对此进行了 深刻反思, 并提出相应的四个改进措施, 以期促进河灯歌节的持续健康发展。

[关键词] 河灯歌节;放河灯; 苗寨歌节

中图分类号：D412.65 文献标识码：A

党的十九大报告指出, 要坚持社会主义核心价值 体系，推动中华优秀传统文化创造性转化、创新性发 展; 坚持在发展中保障和改善民生, 保证全体人民在共 建共享发展中有更多获得感,不断促进人的全面发展、 全体人民共同富裕。广西桂林市资源县政府以发展本 地民俗文化特色为依托, 大力发展旅游业, 在继承地域 民俗节日的同时融合现代文化，使传统文化焕发出新 的生机, 也使资源县人民在发展旅游经济中获益, 提高 了人民的生活质量。陈玉香、周晶晶等人对资源县河灯 歌节的历史由来、发展现状及价值做了一定的分析, 本 文在这一方面也做了部分工作，但在当今竞争激烈的 社会, 我们更应该查漏补缺, 不断反省、提高自身核心 竞争力, 笔者认同朱堶在其文章中表达“许多节日旅游 活动流于形式, 没有内涵” 的观点, 本文的重点之一在 于反思资源县河灯歌节存在的问题。除此之外, 更重要 的是通过一系列措施使河灯歌节更好地发扬传统文化 及改善民生。

\section{1 资源县河灯歌节概况}

\section{1 历史源流}

中国古代有许多传统节日, 一部分源自于古老传 说与民间故事, 一部分源自于宗教信仰。随着社会文明 的不断进步,国家、地区间的交往不断深人,其他国家、 地区的宗教信仰传人中国并得到了吸收发展, 宗教文 化渗透到人们的民俗民情、节日风俗中。

资源县河灯节的由来也与宗教文化密切相关, 唐 时佛教传人资源县境内 (古代称西延), 获得了大批信 徒。由于佛教孟兰盆经中 “目连救母”故事中的悼念追 思、引渡亡魂与中华的祖先崇拜情感相通, 又因资源县 位于资江旁，资江是资源县人民与外界沟通往来的交 通要道, 湘桂两地在水上谋生的人不在少数。每到七月 半的时候, 资江滩多水急, 洪水灾害多, 每年有不少人 在资江溺水身亡,葬身江中。为了给这些冤死的野鬼孤
魂超度, 每年七月半的时候由当地乡珅汼头举办孟兰盆 会, 民众自发参与, 来到江边参加祈福仪式, 点亮河灯, 照 耀水道, 希望为藏身资江的孤魂们照亮投胎的道路, 同时 祈求神明保佑家庭安康, 地产丰盛,兴家旺业。

苗族山歌是劳动人民在日常生产生活中的智慧结 晶, 是对自然万物、生活叙事的真挚表达, 同时也是苗族 人民与众不同的社交方式。关于资源县五排苗歌来源的 传说有三种:一是逃难说, 二是风水说, 三是婚俗说。流传 最广的是逃难说: 香妹千辛万苦逃难到烟竹坪, 逝去的丈 夫托梦给她, 让她努力生活, 并多为他唱些山歌解愁。香 妹在烟竹坪奋力打拼, 在累时唱山歌抒解心怀, 驱散劳 累, 慢慢地把孩子抚养成人, 家族也兴旺了起来。后人为 了纪念祖先辛勤劳作、兴旺家族的历史、学习祖先奋发积 极的生活理念, 在每年的七月半尽情地对唱山歌。这一习 俗不断沿袭至今, 其间几经发展, 形成了唱调丰富多样, 歌词通俗亲切的特色苗歌。

\section{2 发展现状}

资源县政府在 1995 年决定将原集中于县城合浦街 的七月十五放河灯活动与流行于五排三乡的苗寨 “七月 半” 歌节嫁接整合为 “河灯歌节”。从开办至今共举办了二 十五届, 从最初的整合 “河灯节”与 “歌节”开办河灯歌节 到近几年的与其他旅游文化节合办, 以河灯歌节作为推 介, 带动周边旅游景点的发展, 致力于打造一个以河灯歌 节为首, 兼顾天门山景区、丹霞旅游、恣意漂流等旅游项 目的旅游生态系统, 极大促进了资源县旅游产业的发展。 2019 年全县旅游接待总人数达 669.9 万人次, 同比增长 $19.8 \%$; 旅游总消费达 81.2 亿元, 同比增长 $22.1 \%$ 。

得益于现代科技的发展, 从各新闻媒体、社交平台上 发布的关于资源县河灯歌节流程图、时间表及河灯歌节 现场的视频可对河灯歌节有初步的了解。河灯歌节节庆 流程丰富, 有龙狮巡游表演、河灯祈福表演、山歌对唱比 赛、门球赛及其他体育竞技比赛。夜幕降临时进行苗族歌 
舞文艺汇演,夜空中万朵烟花绽放,资江上万戔河灯漂 游。2018 年, 资源县河灯歌节与丹霞文化旅游节共同举 办, 为来自各地的旅客展示了大型实景商业演出 《河灯谣》,并在当晚创造了 10 分钟内 400 人漂放 15680 㙉河灯的纪录, 吸引了无数看客的眼球, 体现了河灯歌 节的热闹非凡。

发展节庆旅游对地方的自然人文环境、社会环境、 基础配套设施、交通等各方面作出了要求,这从侧面推 进了资源县农村文明治理进程, 改善了农村人居条件和 城镇基础设施、公共服务。从资源县政府相关部门近些 年的工作报告中可知, 河灯歌节举办地址周边旅游基础 设施不断完善, 交通道路、公共则所、景区指示标识等基 础设施已经逐步完善并投人使用, 修建了河灯文化长 廊、风雨桥、民俗博物馆等文化休闲娱乐场所。仅 2018 年度, 用于县城提质, 创建县城 $4 \mathrm{~A}$ 级景区等配套设施, 县城交通道路改造等工程的资金就有 1.2 亿元。

\section{3 节日价值}

资源县河灯歌节能将汉苗两民族的民俗文化成功 融合, 体现了中华传统文化的包容性和可塑性, 文化与 商业的结合也将宣扬传统民俗文化与当地经济发展成 功牵线, 在推进当地民俗文化的继承与发展时拓展了资 源县的经济产业链。每年节庆过程中举办的农副产品展 销会为招商引资提供了可靠平台, 为资源县农副产品拓 宽了销路。节庆旅游的发展催生出了许多新的职位需 求, 为人民提供了大量就业岗位, 使当地人民能够在本 地谋生, 减少了当地劳动力流失, 降低了当地留守儿童 率, 提升了资源县人民的家庭幸福感。河灯歌节产于人 民生活, 是资源县人民宝贵的精神财富和共同的民族历 史记忆, 发展河灯歌节传统民俗文化不仅营造出了热闹 吉祥的节日氛围, 在民众追思故人、祈愿家庭美好生活 时也增添了民众的归属感与自豪感。

资源县河灯节从地方习俗演变为对外公开的大型 节庆旅游项目, 研究在这一演变过程中的作用因素及自 然、社会、人文、科技、政策等方面的影响, 于学科而言, 有利于丰富我国旅游开发科学理论; 发展河灯歌节还可 以提高学者对资源县传统民俗文化的关注度, 吸引更多 人才来研究河灯与苗歌的文化内涵, 讲好民俗故事, 探 索、创新河灯歌节的呈现形式, 实现节日旅游和地区民 俗文化的深度融合。

\section{2 河灯歌节存在的问题}

从近年来, 资源县政府紧跟时代潮流的脚步, 不断 挖掘河灯歌节的新内容, 创新河灯歌节的表现形式, 河 灯歌节的内容和形式相比创始之初得到了很大的发展 与改进。但由于社会环境变化与社会经济发展, 各类旅 游项目不断增多、质量不断提升, 人们对旅游项目的要 求和期望随之提高, 旅游市场竞争日趋激烈。资源县河
灯歌节逐渐显露出了一些问题, 使资源县河灯歌节在众 多其他特色节庆旅游竞争中缺乏明显优势。

2.1 节庆流程表演成分居多, 缺乏传统情怀

从往年的资源县河灯歌节相关视频资料了解, 过去 的河灯节在放河灯前会先进行祭祀、烧香点烛化纸、请 道公诵经超度、民众捧着寄托哀思或美好生活愿景的河 灯, 一一走到道公面前听取经文教海, 以获得某种力量 或称之为保佑, 再把河灯放到资江中, 让它照亮故人往 生的道路或自己的人生之路。但从近两年的河灯歌节纪 录视频来看, 河灯歌节的祈福仪式流程十分热闹好看但 缺乏了人与节日之间的情感互动。2019 年的祈福仪式与 河灯歌节一样, 在群众的需求声中不断提升自己。祈福 仪式中融人了苗族传统文化的成分, 如苗王祈福、苗女 着传统服饰跳苗舞等。但从 “苗王”、苗舞的表演者的状 态以及祈福仪式现场的细节看来, 仍较为粗糙, 如苗女 的服饰, 从面料上看并非传统的苗家自制布料, 而是购 买的表演服装; 苗舞带有较强的商业表演; 河灯节作为 汉族节日, 由 “苗王”进行祈福仪式, 非但不显融合之美, 反添杂糅; 用音响播放的苗歌背景音乐更是缺乏让人心 中为之一动的韵味。由此可以看出, 如今的祈福表演逐 渐商业化娱乐化, 场景、祈福配乐都缺乏古朴的意蕴, 并 与民众、旅客的互动性不强, 人们往往仅把祈福仪式当 做一个观赏性节目, 未能在祈福仪式中感受到隐秘的文 化魅力。

\section{2 节庆重点建设及宣传方向重形式轻内涵}

从河灯歌节纪录视频以及各个新闻平台、社交网络 上与河灯歌节相关的宣传来看, 节庆内容近年来越发集 中于放河灯活动的数量、热闹程度和歌舞汇演, 期间穿插 一些运动类赛事, 比如球赛, 忽略了其他传统节日活动, 如斗鸟、斗鸡、舞龙舞狮等富有民族风情的传统活动, 使 本地人民对节日文化的亲切感和自豪感不足, 外地旅客 也缺少在节日旅游中的互动性和投人感, 降低了资源县 河灯歌节的吸引力和独特性, 不利于传统民俗文化的继 承和传播发展。除此之外, 节庆旅游的宣传重点过度迎 合游客爱热闹、喜繁华的心理。重点宣传资源县如何突 破河灯的数量、打造了何种繁华美丽的旅游环境, 而非 宣传、重点建设作为河灯歌节内核之一的“放河灯”活动 本身及最能体现当地民众生活态度的节日娱乐项目。此 举不仅违背了由节日习俗体现当地民众的精神风貌的 初衷, 造成传统文化内涵层面的缺失, 也非引导外地游 客正确感知资源县民俗风情的正确方式。

2.3 河灯制作、苗族歌舞的传承以及创新发展受阻

资源县河灯歌节虽然获得了国家非遗项目的荣誉, 但在时代浪潮的推动下, 许多年轻人选择外出到城市工 作以实现自己的价值、获取更高的收人, 沉下心学习河 灯制作年轻人较少, 且大部分河灯制作者都倾向于研究 
符合现代潮流的河灯扎制技法, 使用传统技法的河灯还 是要靠老师傅来制作。由于河灯歌节的节庆旅游时间段 的限制, 因遭受经济压力, 而不能专心从事河灯的制作 与技术的传播和创新的河灯制作者不在少数。苗族歌舞 的编曲编舞在社会文化环境不断变化的背景下略显陈 旧, 很难吸引在信息爆炸时代背景下成长起来的年轻 人, 这是一个使苗歌苗舞的继承和发展遇到一定阻碍的 重要原因。另一个原因是民族情感教育不到位, 未能使 族内的年轻人充分感受到苗歌苗舞中的重要内涵, 导致 对继承歌舞兴趣缺缺; 对外没有讲好苗歌苗舞的故事, 使旅客在观赏歌舞时仅能停留在欣赏表演的层次, 而不 能深度感受到苗族人民寄托在歌舞里的情感。

\section{3 河灯歌节发展的对策与建议}

结合资源县发展存在的问题, 提出相应的四点建 议:

\section{1 完善节庆仪式流程,深化节日文化内涵}

在设计节庆旅游项目时, 除了将当地特色节日和仪 式列人其中, 并结合其他产业、考虑经济效益的同时, 要 深度挖掘节庆旅游项目的内涵。河灯节的初衷是为逝去 的亡灵祈福超度, 到后来逐渐演变为承载人们对生活的 期望与祈愿, 要达成这一目标仅靠 “放河灯”这一行为是 不能实现的。当代旅游节庆仪式流程应该追源溯本、紧 扣节日形成的初心, 对外讲好传统节日故事, 追溯并尽 可能复原节庆活动的传统流程, 方能使游客对河灯歌节 的节日内涵有更深层次的理解和欣赏。

因此, 在河灯歌节的筹办过程中, 遵循古制增加河 灯与旅客二者之间的祈福互动环节, 用带有宗教色彩的 节庆流程增强节日习俗的神秘感和信念感十分重要。如 将现有的祈福表演一农历十四日晚, 资江江面上搭建 起了祭祀台, 用艺术表现手法加工、再现一场神秘庄严 的祭祀仪式, 更替为道公念咒。在放河灯这一流程之前, 增加游客到道公面前听咒、受点化等环节, 增加游客接 触神秘古老民俗仪式的亲密度、强化文化体验感。

从文化层面上看, 这可以增强人们对民俗文化的兴 趣, 也更符合古代人们放河灯祈福的礼制, 是对古代民 俗文化的追溯和复原, 更是深化民俗文化内涵的重要一 环; 从经济发展层面看, 这凸显了资源县河灯节的民俗 独特性和地方性特点, 对吸引节庆旅游人群、提高地方 节庆旅游的核心竞争力有明显优势。

\section{2 深度挖掘、呈现当地更多特色民俗风情}

河灯歌节是由以合浦街为主的河灯节和五排三乡 的苗族歌节嫁接发展而来, 除了放河灯活动以及苗族歌 舞表演之外, 还有很多富有当地特色的民俗活动, 如从 苗族人民日常劳作中凝练而来, 体现了五排三乡苗族人 民的生活习俗、劳动习惯, 表达美好生活祈愿的“砍山
目一一斗鸡”; 曾经在五排三乡的苗家山寨中流行、后 来随着文化融合、社会进步, 逐渐走出山寨, 走进市区的 “五排油茶”, 喝油茶在苗家寨中有些不成文的规距一 只能用一根筷子、要不多不少地喝四碗…这些规距背后 隐含了五排苗族人民的生活期待与精神信仰, 即使如今 已经很少人遵守或了解这些规距, 但与亲朋好友一起喝 油茶依然是他们的民族默契之一。

朱靘曾对节庆文化内涵的重要性做过如下表述: “文化永远都是发展的内在驱动力, 失去了丰富文化精 神的节庆盛会, 虽有短时的喧器, 但终会流于形式的空 洞,很难长久,对于经济的刺激也不具有长效性”。资源县 有关部门出于精准把握节日主题、实现高效益的节庆旅 游项目目标的考虑, 在筹备节庆旅游时将这些具有人民 日常生活气息的 “小”俗排除在外, 似乎是可以理解 的。但事实上,民众对文化的认同感与亲切感正是寄托 在这些“小”习俗上, 挖掘、展示这些生活习俗可以使当 地民众对河灯歌节的情感更深厚、更发自肺腑, 为资源 县河灯歌节提供专属的民族情感氛围, 弥补大多数民俗 旅游所被诟病的一个缺陷一一流于形式、缺乏文化内 涵。

3.3 结合时代特征, 创新河灯和苗歌苗舞的内容及 表达方式

资源县政府为了提高当地河灯制作工艺水平,传承 河灯制作手艺, 多次举办 “河灯制作大赛”。但由于社会 的发展、科技的进步和教育的普及, 年轻一代的就业选 择愈发多样化, 就业目光大多停驻在一线或其他经济发 展较为繁华的城市。乡镇民族传统产业想要传承与发 展, 须在情感上或薪酬待遇上满足有就业意向的年轻 人, 做好家乡传统民族节庆旅游文化内涵与价值相关宣 传教育, 讲好民族故事, 完善民族文旅产业发展的扶助 政策，保障河灯制作传承者在旅游淡季时的生活水平。

年轻的一代人在广衰的信息田野中奔跑, 采撷了这 个时代最绚丽的思想, 聆听了前所未见的音乐, 少有年 轻人对部分蕴含着陈旧思想, 用词略显粗俗的民族山歌 不加欣赏。但对于一首好歌而言, 歌曲是它的灵魂, 歌词 是它的骨肉, 只要坚定精神, 守住一首歌的精魂, 歌词是 可以由歌者的生活环境、心情状况和所思所想而变化 的, 苗寨山歌的起源也是苗族人民在日常劳作生活中的 所思所想, 因此笔者认为现代苗歌的表演内容也可以根 据现代生活作出一定的改进, 使歌舞内容更贴进我们的 日常生活, 增加歌舞趣味性的同时最大程度地保留苗族 歌舞的特色。同时大力支持、鼓励年轻人使用各种社交、 娱乐社交平台分享苗族歌舞和苗族关文化, 增强苗族歌 舞与外界的交流与互动, 保持新鲜与活力。

\section{4 结语}

从资源县河灯歌节的历史渊源和传统文化习俗背 
景来看, 其文化底蕴厚重; 从过往二十五届河灯歌节节 庆旅游经济成果和发展趋势来看, 其未来可期。在传统 文化习俗与现代商业经济的互动与磨合中, 资源县河灯 歌节在流程仪式、红利覆盖范围、文化内涵、继承发展等 方面显露出了一些不足, 受到了不可避免的市场考验。 但是笔者相信, 以其独特的民俗风情和歌舞风格, 通过 深化节日文化内涵、讲好传统节日故事、拓展旅游项目、 创新歌舞表现内容等方式,资源县河灯歌节能表现出更 浓厚的民族文化吸引力, 能使游客更深度地感受到河灯 歌节的魅力所在, 从而创造更高的民生经济价值及文化 价值。

\section{[课题项目]}

课题来源: 广西文化厅项目一一振兴传统工艺与精 准扶贫研究 (项目编号:20300k5), 广西民族大学 2017 年人才引进项目: 振兴传统工艺与广西精准扶贫的价值 研究 (项目编号:2017MDSKRC13)

\section{[参考文献]}

[1]朱靓. 河灯节与乡村记忆工程 [J]. 城建档案, 2016(11):87-89.

[2]陈玉香.资源县河灯歌节的文化传承及价值研究 [J].新疆石油教育学院学报,2006(02):125-128.

[3]宋富强。民族传统节日产业化转型路径研究 [D]. 广西师范大学, 2013:235.

[4]蔡世保.广南八宝 “孟兰会”河灯节习俗及其功能 探析 [J]. 宿州教育学院学报,2016,19 (02): $138-139+158$.

[5]周晶晶.广西资源县河灯歌节旅游开发问题及对 策[J].旅游纵览(下半月),2018(11):115-116.
[6]金旭明,王荵。资源河灯歌节文化浅析 [J].大众文 艺, 2016(22):24-25.

[7]刘伯浩.河灯歌节逐步实现文化与经济发展的完 美组合[J].当代广西,2011(24):57.

[8]朱鞔.河灯节与乡村记忆工程[J].城建档案, 2016 (11):87-89.

[9]周晶晶.广西资源县河灯歌节旅游开发问题及对 策[J].旅游纵览(下半月),2018(11):115-116.

[10]朱鈽.河灯节与乡村记忆工程 [J].城建档案, 2016(11):87-89.

[11]蔡世保.广南八宝 “孟兰会”河灯节习俗及其功 能探析 [J]. 宿州教育学院学报,2016,19 (02): 138-139+158.

[12]笪方能.资源 “七月半”河灯歌节文化整合的策 略与发展探索[J].中共桂林市委党校学报,2016,16(01): 37-40.

[13]刘伯浩.河灯歌节逐步实现文化与经济发展的 完美组合[J].当代广西,2011(24):57.

[14]陈玉香.资源县河灯歌节的文化传承及价值研 究[J].新疆石油教育学院学报,2006(02):125-128.

[15]金旭明,王惢。资源河灯歌节文化浅析[J].大众 文艺,2016(22):24-25.

\section{作者简介}

闭晓静, 女, 广西南宁人, 1997 年 10 月出生, 广西 民族大学科技史与科技文化研究院 2019 级硕士研究 生;

通讯作者: 邓环, 女, 广西南宁人, 1980 年 10 月出 生,广西民族大学科技史与科技文化研究院副教授. 